\title{
Criminal Law Regulation on Illegal Transplantation of Human Organs in China
}

\author{
Liu Shiwen \\ School of Humanity and Law, Northeastern University \\ Shenyang, Liaoning Province 110169
}

\begin{abstract}
The Amendment to Criminal Law (VIII) issued in 2011 regulates the crime of human organ transplantation, which criminalizes independently the behavior of organizing the sales of human organs. Although this provision makes up for the vacancy in the field of criminal law for organ transplantation in China, there are still some omissions. From the perspective of criminal law regulation of human organ transplantation, this paper strives to provide a reference for how to regulate the criminal liabilities of illegal removal of corpse organs, the crime of human organs trafficking, the crime of smuggling human organs, and the crime of removing organs of mental patients by applying the methods of analyzing articles of law and practical cases. In order to improve the criminal law legislation of human organ transplantation in China, this paper believes that a more detailed and comprehensive legislative proposal must be put forward so as to solve the existing problems of human organ transplantation crimes, and related judicial interpretation and corresponding criminal liabilities shall be issued to cope with the diverse crimes of human organ transplantation.
\end{abstract}

Keywords-Human organ transplantation; The crime of organizing selling human organs; The crime of smuggling human organs

\section{INTRODUCTION}

The technique of organ transplantation increases the recovery rate of patients with organ failure, however, inevitably brings new risks: in recent years, the crime of human organ transplantation has become more and more complicated, infringed on citizens' right to life and health and disturbed the order of medical supervision. Although criminal law of the People's Republic of China is improving the relevant provisions on organ transplant crime, there are still many imperfections. This paper takes the crime of organ transplantation in the judicial practice of our country as the background, mainly studies how to regulate this kind of crime by criminal law and puts forward some relevant suggestions, in order to Improve the regulation of the criminal law on this issue, and provide legal guarantee for the healthy development of organ transplantation technology in China. This paper is divided into three parts: The first part discusses the concept and constitution of the crime of human organ transplantation stipulated in criminal law of our country. The second part confronts the defects in criminal legislation of human organ transplantation in China, mainly expounds that the nature of this kind of criminal act is not reasonable, and the scope of criminal attack is not comprehensive enough. The third part carries on the discussion above how to perfect the criminal law regulation of organ transplantation crime, the crime of illegal removal of living organs, the sale of human organs and the establishment of special crimes against medical personnel and medical institutions are put forward.

\section{THE CONCEPT AND CONSTITUTIVE REQUIREMENTS OF THE CRIME OF HUMAN ORGAN TRANSPLANTATION}

\section{A. The concept of crime of human organ transplantation}

The crime of human organ transplantation is not the name of a specific criminal behavior, but a general term of a new criminal type, which is a generic term of a kind of criminal behavior involving human organ transplantation [1]. Some scholars believe that the criminal behavior of organ transplantation is a general term that violates the social regulations and moral principles, and causes great harm to the society illegally carried out by individuals or organizations. The author recognizes the following definition of the crime of human organ transplantation: The crime of human organ transplantation refers to the generic term of various behaviors related to human organ transplantation carried out by individuals or units, which have serious social harmfulness, seriously infringe upon citizens' right of life and health and disturb the medical treatment and public health order of our country [2].

B. The constitutive requirements of the crime of human organ transplantation

1) The subject of the crime of human organ transplantation

General subject, that is, the individuals or unit organizations. The individual refers to a person over 16 years of age who has self-awareness of the behavior and undertakes the criminal capacity. Among them, the individual subject is usually divided into two types in the crime of human organ transplantation. One type is the doctor while the other is the ordinary being. At the same time, there is a special circumstance that the subject of human organ transplantation is the unit or organization. 
2) Subjective aspects of the crime of human organ transplantation

Generally, the criminal behaviors of organ trade and organ trafficking through deceiving others, compelling others and removing organs of others in order to obtain excessive profits, belong to the category of crime of human organ transplantation. Deceitfully or forcibly removing organs of others under the conditions of being fully aware of unwillingness of others constitutes the subject intent of the crime of human organ transplantation. If the human organs have been removed and sold without consent, an imaginative joint of offense shall be established within the subjective scope of organizing selling of human organs and intentional injury. transplantationation of human organs by due procedure is not the crime within the scope of subject intent.

3) The object of the crime of human organ transplantation

The object of the crime of human organ transplantation refers to the order of medical treatment and public health management. Since once the criminal behavior of human organ transplantation occurs, even if it does not cause physiological harm to the victim or does not involve the situation of endangering the health and life of others, it also violates the order of medical treatment and public health management in our country. The illegal removal of organs disturbs and seriously damages the order of medical treatment and public health management of our country.

4) Objective aspects of the crime of human organ transplantation

Usually, once the crime of human organ transplantation occurs, it will inevitably result in the occurrence of these crimes, including: illegal trafficking of other people's organs, illegal organ transplantation, unauthorized removal of other people's organs, human organs trade and act of purchase and sale without permission, etc. [1]

\section{DEFECTS IN CRIMINAL LEGISLATION OF HUMAN ORGAN TRANSPLANTATION IN CHINA}

The unveil fresh policy of Amendment to Criminal Law VIII provides the basis of criminal law for cracking down on crimes related to human organ transplantation, however, it has certain defects in determining the nature of the criminal behaviors related to human organ transplantation, and the scope of the criminal punishment is not comprehensive enough.

\section{A. Unreasonable determination of the nature of the illegal act of removing a cadaveric organ}

In accordance with the provisions of the Amendment to Criminal Law VIII, for the illegal behaviors of removing the corpse organs, it shall be convicted for the crime of stealing or insulting corpse. The crime of stealing corpse is the secret stealing, which enables the corpse under the actual control. The crime of insulting the corpse, based on strong exposure, indecency, trampling, disfigurement and other subjective culpability of the mind, is a criminal behavior that impairs the dignity of the corpse or injures the godly feelings of the bereaved. The illegal removal of corpse organs is formally consistent with the constitutive elements of a crime of stealing or insulting the corpse, but not all cases are appropriate to be punished by the crime of stealing or insulting the corpse. [1]

In practice, there have been doctors in order to save the lives of patients, the doctor arbitrarily removed the organs of the deceased to bring other patients out of danger without the consent of the deceased's family or any declarations of the deceased for organ donation before their death. Such behavior of doctors is in line with the illegal removal of corpse organs, but the doctors' behavior is not in essence the crime of stealing and insulting the corpse. First of all, although the doctors removed the organs of the deceased without the family knowing it, which conforms to the secret stealing in the crime of stealing the corpse. Nevertheless, the doctors did not have the subjective purpose of illegal encroachment of organs, which did not constitute the crime of stealing the corpse. Doctors remove organs to save people, and there is no subjective intention of insulting the corpse, therefore, the doctors' behavior is consistent with the illegal removal of organs, while can not be convicted of stealing or insulting the corpse.

\section{B. Criminal liability for the crime of human organs trafficking has not yet been stipulated}

In order to better implement the Regulations on Human Organ transplantationation, the Ministry of Health issued the Regulations on Stipulating Living Organ transplantationation in 2009, of which generally stipulates that medical institutions and their medical personnel who buy and sell living organs or engage in activities related to the sale and purchase of living organs shall be handed over to the judicial authorities for investigation when the circumstances are so serious as to constitute the crime. However, the Amendment to Criminal Law VII does not have regulations on the criminal liability of the sale and purchase of human organs for both parties.

The behavior of buying and selling human organs is prohibited all over the world. The system of free organ donation has been established in our country and it is forbidden to buy and sell human organs. The organ resource is extremely short, and the sale and purchase of organs has the huge market, which can obtain the high income. If not prohibited, people may do things that may harm to others for the sake of money, which stimulates the crime. [2]

\section{Criminal liability for the crime of smuggling human organs has not yet been established}

Human organ smuggling refers to the behaviors of violating customs regulations, evading customs supervision, carrying, transporting and mailing human organs for the exit and entry. Such behavior is a kind of serious criminal act which infringes not only the order of customs management, but also medical management. Many countries have specific crimes of smuggling human organs in their criminal laws. Our country shall also conform to the international trend and establish a related crime to crack down on this crime of smuggling organs, and resist such illegal and criminal acts together with other countries, so as to maintain the stability of the world. [1] 


\section{Criminal liability for removal of organs of mental patients has not yet been established}

The Amendment to Criminal Law (VIII) stipulates that if removal of body organs from a minor under 18 years of age [2], it shall be convicted and punished for the crime of intentional injury or intentional homicide, which reflects the protection of minors in the criminal law of our country. A minor under the age of 18 does not have full capacity for civil conduct. If one agrees to donate his body organs, such agreement shall have no legal effect. Similarly, the mental patients also do not have the full capacity for civil conduct, and also should receive the same protection from the criminal law. The mental patients are very similar to the minors in their cognition of things, and even sometimes the mental patients are not as good as the minors in their cognition of things. Therefore, in organ transplantationation, there should be no omission of the provisions for mental patients. However, the Amendment to Criminal Law (VIII) leaves out criminal liability for the removal of organs of mental patients.

\section{IMPROVEMENT OF CRIMINAL LEGISLATION OF HUMAN ORGAN TRANSPLANTATIONATION}

\section{A. Establishment of the crime of illegal removal of living organs}

As previously mentioned, for the illegal removal of living organs, it is inappropriate for all persons to be convicted and punished with the crime of intentional injury or intentional homicide. There shall be an additional charge in the criminal law, that is, the crime of illegal removal of living organs. For those who remove living organs by means of violence, coercion, deception, or the organs removal of minors under the age of 18 , or the organs removal of mental patients who do not have the capacity for civil conduct, they shall be convicted and punished for the crime of illegal removal of living organs if having not caused injury or caused harm below the level of serious injury. Where serious injury or death is caused, the provisions of the Amendment to the Criminal Law (VIII) shall apply, and the illegal removal of living organs shall be converted into the act of intentional injury or homicide, which shall be convicted and punished with the crime of intentional injury or intentional homicide.

\section{B. Establishment of the crime of buying and selling human organs}

Major countries in the world have passed laws prohibiting the purchase and sale of human organs and stipulated the trading of human organs as the crime without exception, such as the United Kingdom, the United States, Germany, Japan, Australia, and so on [1/ ]Although the law of our country also prohibits the purchase and sale of human organs, the criminal law only prescribes the behavior of organizing sales of human organs as the crime, and takes an indulgent attitude towards the illegal purchase and sale of human organs, which is very unfavorable to crack down on the crime of human organ transplantation. Therefore, the crime of buying and selling human organs should be added to the criminal law of our country, so as to fight and restraint such criminal act.

\section{Establishment of the crime of smuggling human organs}

Due to the particularity of human organs, the market scope of human organ source is constantly expanding. Transnational smuggling of human organ becomes more and more frequent, and even specialized transnational organizations with supply and marketing integration of human organs have emerged. The performance of criminal behavior of smuggling human organs is that they violate the regulations of the customs, evade the supervision of the customs, carry, transport and mail human organs illegally for exist and entry by means of deception and camouflage. This kind of behavior not only infringes the customs system of our country, but also violates the medical treatment order of our country, which is no less harmful than the smuggling of drugs, guns, ammunition, explosives and so on. Therefore, it is necessary to add the crime of smuggling human organs in our criminal law in order to effectively crack down on this kind of criminal behavior [2].

\section{Improvement in the regulations of criminal law on the illegal organ removal of mental patients}

Although the Amendment to Criminal Law (VIII) regulates the criminal liability for the removal of organs of minors under the age of 18, it ignores the criminal law protection for the mental patients. There are many similarities between mental patients and minors in identification and control capacity, and they can not determine the donation of their own body organs. Both of them are vulnerable groups and deserve the same protection from criminal law. As a result, the criminal law should also stipulate that the removal of organs of mental patients shall constitute the crime of illegally removing living organs. The removal of organs resulting in serious injury or death of mental patients shall be transformed into the crime of intentional injury or intentional homicide. However, considering that the intermittent mental patients are not exactly the same as the minors, they are allowed to make decisions to donate their own body organs when their mental disease is not onset with normal mental state and has the complete identification and control capacity. The criminal law should recognize the validity of this kind of donation decision, and if the body organ is removed according to the valid donation decision, it shall not be criminalized.

\section{CONCLUSION}

There is no doubt that a perfect legal system can regulate the order of organ transplantation and facilitate the career development of organ transplantation. But at present, there are few criminal laws and regulations about human organ transplantation in our country, and the laws and regulations are vague, with a large amount of blanks and loopholes. Therefore, it is required for our country to strengthen the addition of new crime for human organ transplantation, to give a specific punishment and sentencing, to effectively regulate the behavior of organ transplantation in China, to establish a comprehensive organ transplantation legal system and specific regulations and judicial interpretation based on the situation of China against the background of internationalization. At the same time, the criminal law regulation of organ transplantation should be accelerated according to the manifestation and criminal liability of organ transplantation crime, which will promote the rapid 
development of human organ transplantation in our country. As the last barrier to safeguard the rights and interests of citizens, the criminal law should probe into the social harm brought by such behavior from a more strict angle, and make sufficient theoretical preparation for the illegal organ transplantation.

\section{REFERENCES}

[1] Yang Liqiong, Analysis of the Legislation Problems in Human Organ Transplantation in Our Country [J]. Journal of Southwest Jiaotong University: Social Sciences 2011,12(5):136-141.

[2] Dai Shifu. Study on Criminal Law Regulation of Human Organ Transplantation in China [D]. Changchun: Northeast Normal University,2013.

[3] Xue Pei. Human Organ Transplantation and its Criminal Jurisprudence Analysis[J]. Oriental Law,2011(01):120.

[4] Chen Fang. Study on Criminal Law of Human Organ Transplantation[D]. Shanghai: East China University of Political Science and Law,2013:3031.

[5] Wang Jun. On the Criminal Law Regulation of the Human Organ Transplantation[D]. Suzhou: Suzhou University,2013:34-35.

[6] Ma Zhangmin. Criminal Law Regulation of Human Organ Transplantation[J]. Journal of Shandong Police College,2013(6):46-50.

[7] Liu Chen, Gu Jinxian. Human Organ Transplantation from the Perspective of Criminal Law[J]. Medical Law,2016(10):81-84.

[8] Xiong Yongming. A Brief Review on the Criminal Law Issue of Organ Transplantation in China[J]. Medicine and Law, 2012, 4(05):5-12. 